\title{
MicroRNA-191-5p exerts a tumor suppressive role in renal cell carcinoma
}

\author{
PEIJIE CHEN ${ }^{1-3^{*}}$, XIANG PAN $^{1,3^{*}}$, LIWEN ZHAO $^{1}$, LU JIN $^{1,3}$, CANBIN LIN $^{1-3}$, JING QUAN $^{1,3}$, TAO HE $^{1,3}$, \\ LIANG ZHOU ${ }^{1,3}$, XUELING WU $^{4}$, YONG WANG ${ }^{5}$, LIANGCHAO NI $^{1}$, SHANGQI YANG ${ }^{1}$ and YONGQING LAI ${ }^{1,3}$ \\ ${ }^{1}$ Department of Urology, Peking University Shenzhen Hospital, Shenzhen, Guangdong 518036; \\ ${ }^{2}$ Department of Urology, Shantou University Medical College, Shantou, Guangdong 515041; ${ }^{3}$ The Guangdong and \\ Shenzhen Key Laboratory of Male Reproductive Medicine and Genetics, Peking University Shenzhen Hospital, \\ Institute of Urology of Shenzhen PKU-HKUST Medical Center, Shenzhen, Guangdong 518036; \\ ${ }^{4}$ Department of Urology, Longgang District Central Hospital of Shenzhen, Shenzhen, Guangdong 518116; \\ ${ }^{5}$ Department of Reproduction, Peking University Shenzhen Hospital, Shenzhen, Guangdong 518036, P.R. China
}

Received May 6, 2017; Accepted August 10, 2017

DOI: $10.3892 / \mathrm{etm} .2017 .5581$

\begin{abstract}
Renal cell carcinoma (RCC) is a common tumor of the urinary system. Previously, miR-191-5p has been reported to be associated with various types of cancer; however, its specific functions in RCC have not been investigated to date. In the present study, the expression of miR-191-5p in the 786-O and ACHN cell lines was detected in vitro by reverse transcription-quantitative polymerase chain reaction (RT-qPCR). The results of RT-qPCR revealed that miR-191-5p was significantly downregulated in the two cell lines compared with the $293 \mathrm{~T}$ cell line. miR-191-5p was also significantly downregulated in RCC tissue compared with paired normal tissue. In addition, the effects of miR-191-5p on cell proliferation, migration, invasion and apoptosis were examined by CCK-8, MTT, wound scratch, Transwell and flow cytometry assays. Downregulation of miR-191-5p was observed to promote cell proliferation, migration and invasion, as well as to repress the cell apoptosis of 786-O and ACHN cells. Therefore, the current study suggests that miR-191-5p functions as a tumor suppressor in RCC. Further studies are required to uncover the underlying signaling pathway of miR-191-5p and its potential role as a biomarker for early detection and prognosis prediction, and as a therapeutic target of RCC.
\end{abstract}

Correspondence to: Professor Yongqing Lai, Department of Urology, Peking University Shenzhen Hospital, 1120 Lianhua Road, Shenzhen, Guangdong 518036, P.R. China

E-mail: yqlord@163.com

*Contributed equally

Key words: microRNA, microRNA-191-5p, renal cell carcinoma, suppressor

\section{Introduction}

Renal cell carcinoma (RCC) accounts for $\sim 2 \%$ of all cancer diagnoses and cancer-associated mortalities, with $\sim 295,000$ new kidney cancer cases are diagnosed and $~ 134,000$ mortalities recorded worldwide annually (1). RCC is classified into three major subtypes, including clear cell, papillary and chromophobe RCC. Clear cell RCC is the most common subtype accounting for approximately $75 \%$ of all RCC cases (2). According to the American Joint Committee on Cancer staging of RCC (3), the 5-year survival rate of patients with stage I RCC is $\sim 98 \%$, while that of patients with stage III is $\sim 5 \%$ (4). Thus, early detection and treatment is important. However, $\sim 33 \%$ of patients have metastatic disease at the time of diagnosis, and $30-40 \%$ of patients relapse subsequent to the initial nephrectomy $(5,6)$. Therefore, there is also a pressing need for effective diagnosis and treatment.

microRNAs (miRNAs or miRs) are short non-coding single stranded RNAs of 20-22 nucleotides in length that regulate the gene expression at the post-transcriptional level (7). Emerging evidence revealed that miRNAs are aberrantly expressed in numerous types of human cancer, as well as serve important roles in the initiation, development and metastasis of cancer (8-10). miRNAs also function as oncogenes or tumor suppressors in various cancer types (11). Previous studies have demonstrated that certain miRNAs were associated with RCC carcinogenesis, upregulated miRNAs act as tumor activator whereas downregulated miRNAs act as tumor suppressors (12-14). miR-191-5p is known to be dysregulated in several tumors, including intrahepatic cholangiocarcinoma (15), breast cancer (16) and colorectal cancer (17). However, the role of miR-191-5p in RCC remains largely unknown.

Therefore, the aims of the current study were to detect the expression of miR-191-5p in the ACHN and 786-O cell lines, as well as to reveal the function of miR-191-5p on the cell proliferation, invasion, migration and apoptosis in RCC. 


\section{Materials and methods}

Sample collection. A total of 24 pairs of RCC and adjacent normal renal tissues were collected from Peking University Shenzhen Hospital (Shenzhen, China). The characteristics of the patients from whom tissues were collected are presented in Table I. The only inclusion criterion was that the patient had RCC, there were no exclusion criteria. Written informed consent was obtained from each patient. The study protocol conformed to the ethical guidelines of the 1975 Declaration of Helsinki, and was approved by the Research Ethics Committee of Peking University Shenzhen Hospital (Shenzhen, China). Tissues were dissected, immersed in RNAlater (Qiagen $\mathrm{GmbH}$, Hilden, Germany) for $30 \mathrm{~min}$ and stored at $-80^{\circ} \mathrm{C}$ until use. Each pair of tissues consisted of RCC tissues along with adjacent normal tissues at $2 \mathrm{~cm}$ distant from the visible RCC lesions. Primary tumor stage and Fuhrman nuclear grading system were used to classify the specimens $(18,19)$.

Cell culture. The 786-O and ACHN RCC cell lines, as well as $293 \mathrm{~T}$ human embryonic kidney cells, were obtained from the American Type Culture Collection (Manassas, VA, USA). $786-\mathrm{O}$ cells were cultured in a $37^{\circ} \mathrm{C}$ humidified incubator containing 5\% $\mathrm{CO}_{2}$ with RPMI 1640 medium (Gibco; Thermo Fisher Scientific, Inc., Waltham, MA, USA), while ACHN and 293T cells were cultured with Dulbecco's modified Eagle medium (Gibco; Thermo Fisher Scientific, Inc.) at the same temperature and humidity. Media were supplemented with $10 \%$ fetal bovine serum and $1 \%$ antibiotics $(100 \mu \mathrm{l} / \mathrm{ml}$ penicillin and $100 \mathrm{mg} / \mathrm{ml}$ streptomycin sulfates; Pen Strep) and 1\% glutamine (all from Gibco; Thermo Fisher Scientific, Inc.).

$R N A$ extraction and reverse transcription-quantitative polymerase chain reaction $(R T-q P C R)$. Total RNA was extracted from the tissues by TRIzol (Life Sciences; Thermo Fisher Scientific, Inc.) and purified with the RNeasy Maxi kit (Qiagen $\mathrm{GmbH}$ ) according to the manufacturer's protocol. Next, the RNA concentration in the sample was detected with a NanoDrop 2000/2000c spectrophotometer (Thermo Fisher Scientific, Inc.). cDNA synthesis was performed at $7^{\circ} \mathrm{C}$ for $60 \mathrm{~min}, 95^{\circ} \mathrm{C}$ for $5 \mathrm{~min}$, the products were stored at $4^{\circ} \mathrm{C}$. RT was conducted using $1 \mu \mathrm{g}$ total RNA of each sample according to the procedure described in the miScript Reverse Transcription kit (Qiagen $\mathrm{GmbH}$ ). Subsequently, qPCR was performed to detect the expression of miR-191-5p with the miScript SYBR Green PCR kit (Qiagen $\mathrm{GmbH}$ ) on the Roche Lightcycler 480 Real-Time PCR system (Roche Diagnostics, Basel, Switzerland) according to the manufacturer's protocols. The primers for miR-191-5p and U6 (serving as the internal control) used in QPCR assay are listed in Table II, they were produced by Invitrogen (Thermo Fisher Scientific, Inc.). The qPCR thermal cycling conditions were as follows: $95^{\circ} \mathrm{C}$ for $1 \mathrm{~min}$, followed by 40 cycles of $95^{\circ} \mathrm{C}$ for $15 \mathrm{sec}, 55^{\circ} \mathrm{C}$ for $30 \mathrm{sec}$ and $72^{\circ} \mathrm{C}$ for $30 \mathrm{sec}$. The expression of miR-191-5p was calculated according to the $2^{-\Delta \Delta \mathrm{Cq}}$ method (20).

Cell transfection. In order to upregulate the expression level of miR-191-5p in 786-O and ACHN cells, transfection was performed with synthesized miR-191-5p mimics (GenePharma, Inc., Shanghai, China). For downregulation
Table I. Clinicopathological features of patients with renal cell carcinoma.

\begin{tabular}{lc}
\hline Characteristic & Value \\
\hline Mean age (range), years & $44(25-62)$ \\
Males, $\mathrm{n}$ & 9 \\
Females, $\mathrm{n}$ & 15 \\
Histological type, $\mathrm{n}$ & \\
Clear cell & 21 \\
Papillary & 3 \\
pT-stage, $\mathrm{n}$ & \\
T1 & 19 \\
T2 & 3 \\
T3+T4 & 2 \\
Fuhrmann grade, $\mathrm{n}$ & \\
I & 3 \\
II & 17 \\
III & 2 \\
IV & 2 \\
AJCC clinical stage, $\mathrm{n}$ & \\
I & 8 \\
II & 14 \\
III + IV & 2 \\
\hline
\end{tabular}

pT, primary tumor; AJCC, American joint committee on cancer.

of the expression, cells were transfected with a synthesized miR-191-5p inhibitor (GenePharma, Inc.). Lipofectamine 2000 (Invitrogen; Thermo Fisher Scientific, Inc.) mixed in the Opti-MEMR I Reduced Serum Medium (Gibco Thermo Fisher Scientific, Inc.) was used for transfection, following the manufacturer's instructions. The expression level of miR-191-5p was monitored by RT-qPCR to determine whether upregulation or downregulation was successful. The sequences of the miRNAs and negative control (NC) mimics and inhibitors used are listed in Table II.

Wound scratch assay. The effect of miR-191-5p the migration of 786-O and ACHN cells was investigated by a wound scratch assay. Briefly, approximately $3 \times 10^{5}$ cells were seeded into each well of a 12-well plate, and transfected with 40 pmol miR-191-5p mimics, miR-191-5p inhibitor, NC mimics or NC inhibitor after $24 \mathrm{~h}$ using Lipofectamine 2000. The cell monolayer was scraped in a straight line using a micropipette tip and washed with phosphate-buffered saline (PBS; Gibco; Thermo Fisher Scientific, Inc.) to remove any cell debris after $6 \mathrm{~h}$ of transfection. Subsequently, the scraped monolayer was incubated at $37^{\circ} \mathrm{C}$ in a humidified chamber containing $5 \% \mathrm{CO}_{2}$. A digital camera system (Olympus Corporation, Tokyo, Japan) was used to capture images of the scratches at 0 and $12 \mathrm{~h}$ after the scratch through a Leica DMIRB inverted fluorescence microscope (Leica Microsystems GmbH, Wetzlar, Germany).

Transwell assay. The effect of miR-191-5p on the migration and invasion of 786-O and ACHN cells was measured by 
Table II. Sequences of primers and microRNAs.

Primer or miRs Sequence

miR-191-5p

U6

miR-191-5p mimics

NC mimics

miR-191-5p inhibitor

NC inhibitor
Forward: 5'-CAACGGAATCCCAAAAGCAGCTG-3' Reverse: As provided by the miScript SYBR Green kit Forward: 5'-CTCGCTTCGGCAGCACA-3' Reverse: 5'-ACGCTTCACGAATTTGCGT-3' Forward: 5'-CAACGGAAUCCCAAAAGCAGCUG-3' Reverse: 5'-GCUGCUUUUGGGAUUCCGUUGUU-3' Forward: 5'-UUCUCCGAACGUGUCACGUTT-3' Reverse: 5'-ACGUGACACGUUCGGAGAATT-3' 5'-CAGCUGCUUUUGGGAUUCCGUUG-3' 5'-CAGUACUUUUGUGUAGUACAA-3'

miR, microRNA; NC, negative control.

conducting a transwell assay. Transwell chamber inserts (BD Biosciences, Franklin Lakes, NJ, USA) with (for invasion) or without Matrigel (for migration) were used in the assay according to the manufacturer's protocol. Briefly, $200 \mu \mathrm{l}$ serum-free medium containing $\sim 1 \times 10^{4}$ transfected cells was plated in the upper compartment of the chamber. Complete medium as the source of chemo-attractants was added into the lower chamber. The migration time was $36 \mathrm{~h}$ in the two cell lines, while the invasion time was 48 and $60 \mathrm{~h}$ in 786-O and ACHN cells, respectively. Cells that had migrated to or invaded the lower surface of the inserts were then stained with $0.1 \%$ crystal violet (Sigma-Aldrich; Merck KGaA, Darmstadt, Germany) and were counted under the microscope at magnification, x100 (Leica Microsystems GmbH).

MTT assay. The cell proliferation analysis was conducted by 3-(4,5-dimethylthiazol-2-yl)-2,5-diphenyltetrazolium bromide (MTT) assay. Briefly, 5,000 cells were seeded into each well of a 96-well plate, and then 5 pmol miR-191-5p mimics, miR-191-5p inhibitor, NC mimics or NC inhibitor was used for transfection. At 4 days after transfection, $20 \mu \mathrm{l} \mathrm{MTT}$ ( $5 \mathrm{mg} / \mathrm{ml}$; Sigma-Aldrich; Merck KGaA) was added into the medium, which was replaced by $100 \mu 1$ dimethyl sulfoxide (Sigma-Aldrich; Merck KGaA) after 4 h. The experimental wells were shaken by a reciprocating decolorization shaking table (TSB-108; Qilinbeier, Jiangsu, China) for $10 \mathrm{~min}$ in the dark, and then the absorbance was read at $595 \mathrm{~nm}$ on an ELISA microplate reader (Bio-Rad Laboratories, Inc., Hercules, CA, USA).

Cell counting kit-8 (CCK-8) assay. CCK-8 assay was performed to detect the cell proliferation ability of 786-O and ACHN cells in vitro. Approximately 5,000 cells were seeded into each well of a 96-well plate. Following incubation for $24 \mathrm{~h}$, the cells were transfected with 5 pmol miR-191-5p mimics, inhibitor, NC mimics or NC inhibitor. At $0,24,48$ and $72 \mathrm{~h}$ after transfection, $10 \mu \mathrm{l}$ CCK-8 (Beyotime Institute of Biotechnology, Haimen, China) was added to each well and incubated for $30 \mathrm{~min}$. Subsequently, the absorbance values of the experimental wells were detected at $490 \mathrm{~nm}$ on a ELISA microplate reader (model 680; Bio-Rad Laboratories, Inc.).
Flow cytometry assay for apoptosis detection. In order to detect the apoptotic rates of 786-O and $\mathrm{ACHN}$ cells in vitro, flow cytometry assay was performed. Briefly, $\sim 3 \times 10^{5}$ cells were seeded into each well of a 6-well plate and then transfected with 200 pmol miR-191-5p mimics, inhibitor, NC mimics or $\mathrm{NC}$ inhibitor. After $48 \mathrm{~h}$, the cells were collected and washed with cold PBS, and then resuspended with $100 \mu 1 \mathrm{X}$ binding buffer. Next, $5 \mu \mathrm{l}$ Annexin V-fluorescein isothiocyanate and $5 \mu \mathrm{l}$ propidium iodide (Invitrogen; Thermo Fisher Scientific, Inc.) were added to each cell suspension. After $15 \mathrm{~min}$ of staining in the dark at room temperature, $400 \mu \mathrm{l}$ binding buffer was added to each tube. The data were collected and analyzed on an EPICS XL-4 flow cytometer (Beckman Coulter, Inc., Brea, CA, USA).

Statistical analysis. Paired t-tests were used to compare the expression levels of miR-191-5p in the matched tumor and normal tissues, or in the different cells. Student's t-test was used to analyze assays for characterizing phenotypes of cells. All the statistical analyses were conducted using SPSS version 19.0 (IBM SPSS, Armonk, NY, USA). P<0.05 was considered to indicate a statistically significant difference.

\section{Results}

miR-191-5p is downregulated in RCC clinical specimens and cell lines. The ratio of miR-191-5p expression in 24 paired clinical specimens was presented in Fig. 1A as the $\log _{2}$ ratio of tumor over adjacent normal tissues. The expression of miR-191-5p in RCC tissues was significantly downregulated compared with that in adjacent normal tissues $(\mathrm{P}<0.01$; Fig. 1B). In addition, the expression of miR-191-5p in the 293T normal human embryonic kidney cell line was significantly upregulated compared with that in ACHN $(\mathrm{P}<0.05)$ and 786-O $(\mathrm{P}<0.001)$ RCC cell lines, which was in accordance with the expression pattern of miR-191-5p in the clinical specimens (Fig. 1C).

Transfection efficiency validation. miR-191-5p or NC mimics, and miR-191-5p or NC inhibitors were transfected into 786-O and ACHN cells and the transfection efficiency was evaluated by RT-qPCR. As observed in Fig. 1D, the expression levels 
A

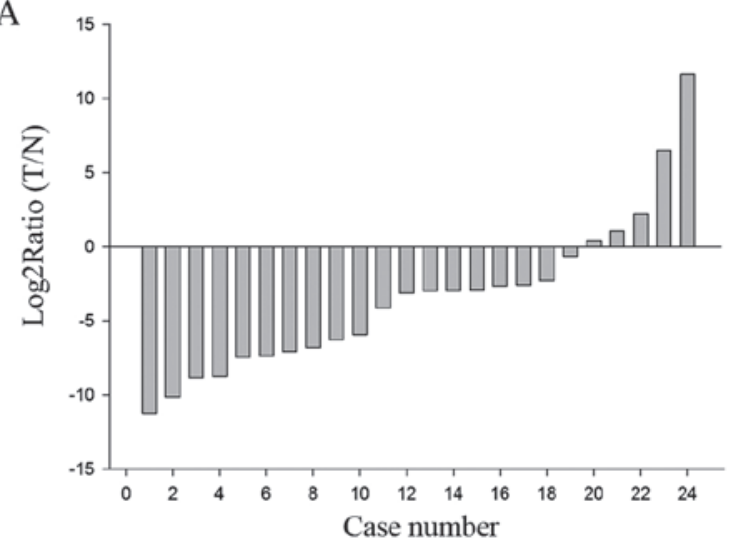

$\mathrm{C}$

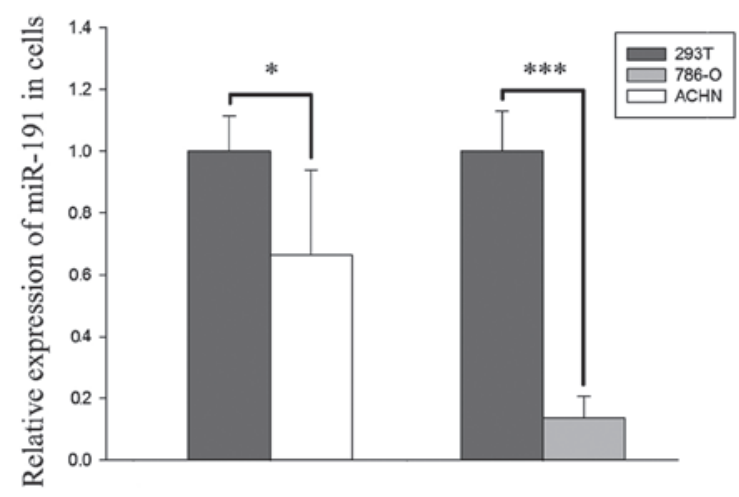

B

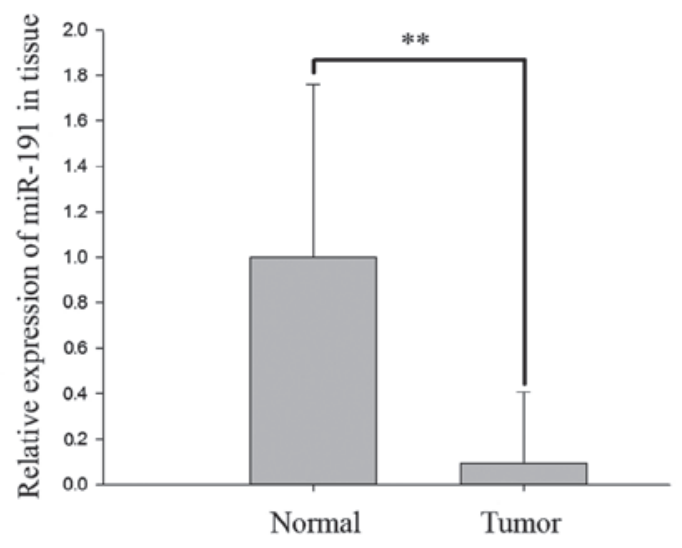

$\mathrm{D}$

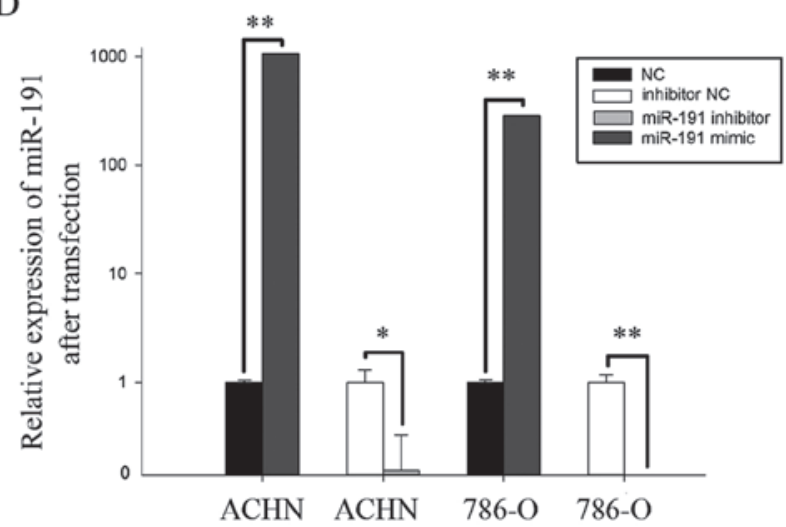

Figure 1. (A) $\log _{2} \mathrm{~T} / \mathrm{N}$ ratio of miR-191-5p, and (B) relative expression of miR-191-5p in 24 paired clinical specimens of RCC and adjacent normal tissues. (C) Relative expression levels of miR-191-5p in the normal 293T cells and two RCC cell lines (ACHN and 786-O). (D) Relative expression levels of miR-191-5p in ACHN and 786-O cell lines after transfection with mimics or inhibitors. ${ }^{*} \mathrm{P}<0.05,{ }^{* *} \mathrm{P}<0.01$ and ${ }^{* * * *} \mathrm{P}<0.001$. RCC, renal cell carcinoma; miR, microRNA; NC, negative control; T, RCC tissues; $\mathrm{N}$, normal tissues.

of miR-191-5p were downregulated by $84.57 \%$ in ACHN cells $(\mathrm{P}<0.05)$ and $98.75 \%$ in $786-\mathrm{O}$ cells $(\mathrm{P}<0.01)$ following transfection with the miR-191-5p inhibitor as compared with $\mathrm{NC}$ inhibitor, while the expression levels of miR-191-5p were $1,062.56$ times higher in ACHN cells $(\mathrm{P}<0.01)$ and 283.39 times higher in $786-\mathrm{O}$ cells $(\mathrm{P}<0.01)$ following transfection with miR-191-5p mimics compared with the corresponding $\mathrm{NC}$ group.

Upregulation of miR-191-5p suppresses RCC cell proliferation, while downregulation promotes RCC cell proliferation. A CCK- 8 assay was used to observe whether differential expression of miR-191-5p affected the proliferative ability of the RCC cells. The proliferative ability of the miR-191-5p mimic group in the ACHN cells was significantly decreased by $11.16 \%(\mathrm{P}<0.05), 14.83 \%(\mathrm{P}<0.05)$ and $20.83 \%(\mathrm{P}<0.001)$ at 24,48 and $72 \mathrm{~h}$ after transfection, respectively, compared with the NC group (Fig. 2A). By contrast, cell proliferation in the miR-191-5p inhibitor group was increased by $5.55 \%$ $(\mathrm{P}>0.05), 19.92 \%(\mathrm{P}<0.01)$ and $25.24 \%(\mathrm{P}<0.05)$ at 24 , 48 and $72 \mathrm{~h}$ after transfection, respectively (Fig. 2B). Similarly, in the 786-O cells, the proliferation rates of the miR-191-5p mimic group were significantly decreased by $11.13,24.34$ and $24.49 \%$ at 24,48 and $72 \mathrm{~h}$ after transfection, respectively $(\mathrm{P}<0.05, \mathrm{P}<0.01$ and $\mathrm{P}<0.01$; Fig. $2 \mathrm{C})$, while the rates of proliferation increase in the miR-191-5p inhibitor-transfected cells were 8.26, 9.91 and $19.70 \%$ at 24, 48 and $72 \mathrm{~h}$, respectively ( $\mathrm{P}<0.05$; Fig. 2D).

Upregulation of miR-191-5p suppresses RCC cell viability, while downregulation promotes RCC cell viability. The viability of miR-191-5p was also assessed using MTT assay. As shown in Fig. 2E, the viability of the miR-191-5p mimic group was decreased by $17.97 \%$ in the ACHN cells compared with the corresponding $\mathrm{NC}$ group $(\mathrm{P}<0.05)$, while the viability of the miR-191-5p inhibitor group was promoted by $29.41 \%$ $(\mathrm{P}<0.05)$. Similarly, in $786-\mathrm{O}$ cells, the viability of the miR-191-5p mimic group was decreased by $19.12 \%(\mathrm{P}<0.05)$, while that of the miR-191-5p inhibitor group was promoted by $10.18 \%$ (P<0.05; Fig. 2F).

Upregulation ofmiR-191-5p suppresses RCC cellmobility, while downregulation of miR-191-5p promotes RCC cell mobility. Cell mobility was examined by a wound scratch and transwell assays. The results of the wound scratch assay suggested that the migratory distance of 786-O cells transfected with miR-191-5p mimic was decreased by $37.55 \%(\mathrm{P}<0.01$; Fig. $3 \mathrm{~A}$ and $\mathrm{B})$ and by $34.28 \%$ ( $\mathrm{P}<0.05$; Fig. 3A and $\mathrm{C}$ ) in ACHN cells, as compared with the corresponding NC group. By contrast, the increase in the migration rate following transfection with miR-191-5p inhibitor were $31.00 \%$ for $786-\mathrm{O}$ cells $(\mathrm{P}<0.05$; Fig. $3 \mathrm{~A}$ and $\mathrm{B})$ and $46.15 \%$ for ACHN cells $(\mathrm{P}<0.01$; Fig. $3 \mathrm{~A}$ and $\mathrm{C})$. 
A

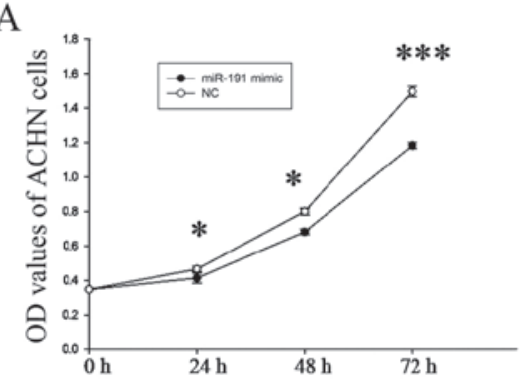

C

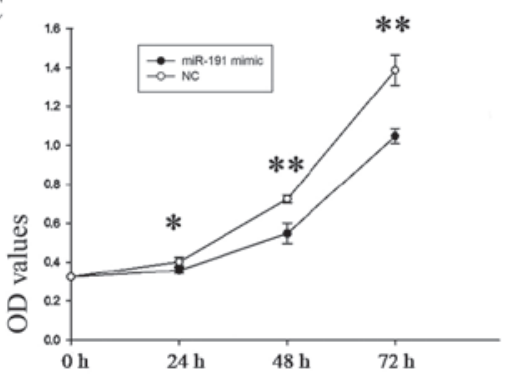

E

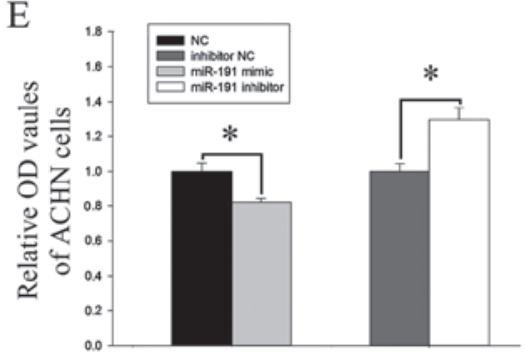

B

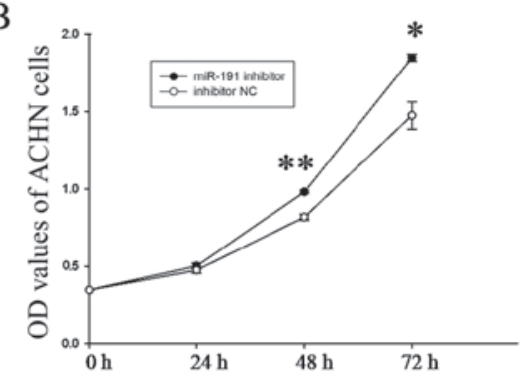

D

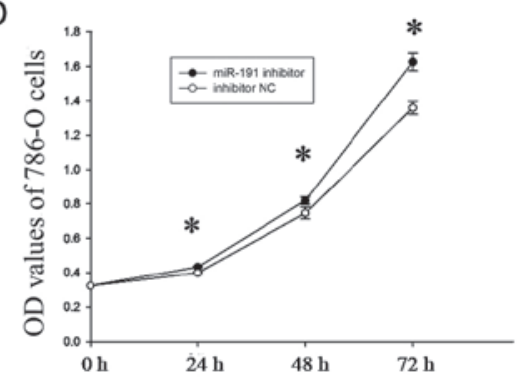

F

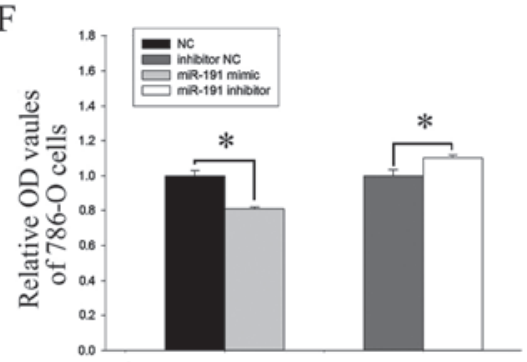

Figure 2. Analysis of proliferative ability using cell counting kit-8 assay in ACHN cells transfected with miR-191-5p (A) mimic and (B) inhibitor, and in 786-O cells transfected with miR-191-5p (C) mimic and (D) inhibitor. Analysis of viability in (E) ACHN and (F) 786-O cells using MTT assay. "P<0.05, ** P<0.01 and ${ }^{* * *} \mathrm{P}<0.001$. miR, microRNA; NC, negative control; OD, optical density.

A<smiles>[AlH2]NC1CCC1</smiles>

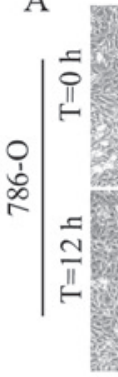

$\mathrm{NC}$
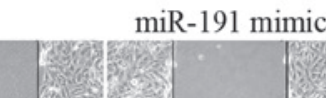
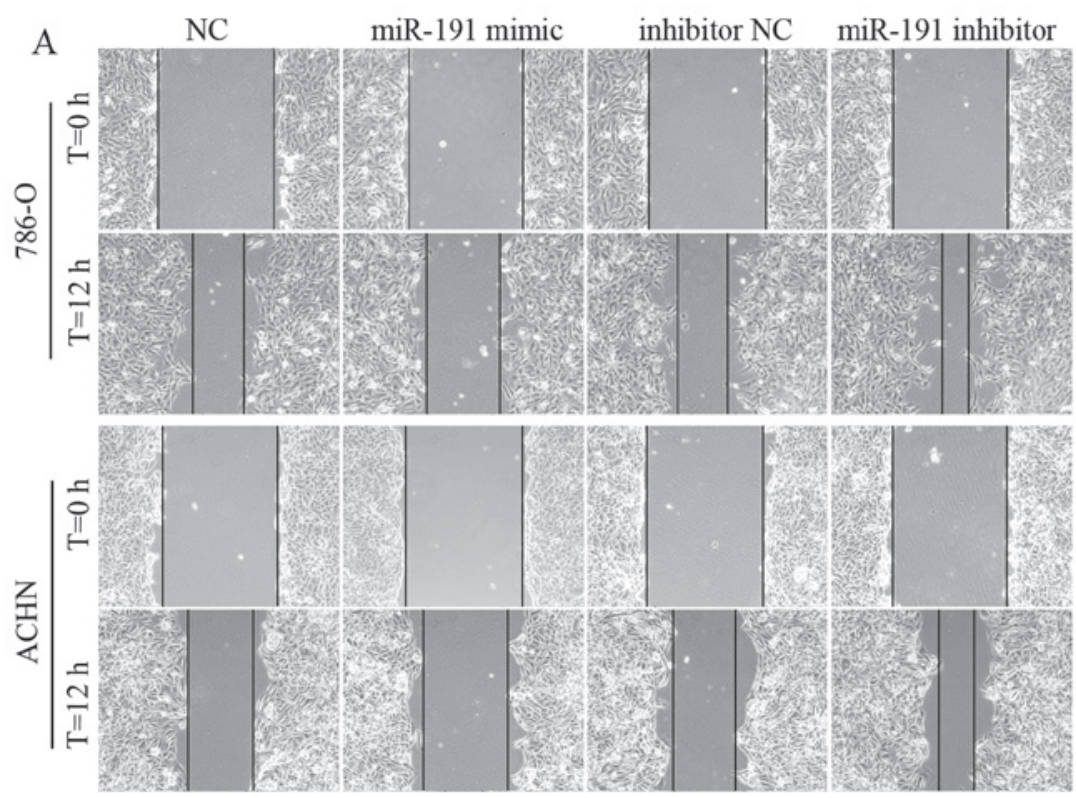

B

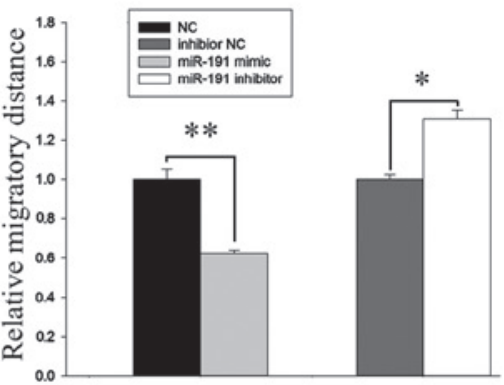

$\mathrm{C}$

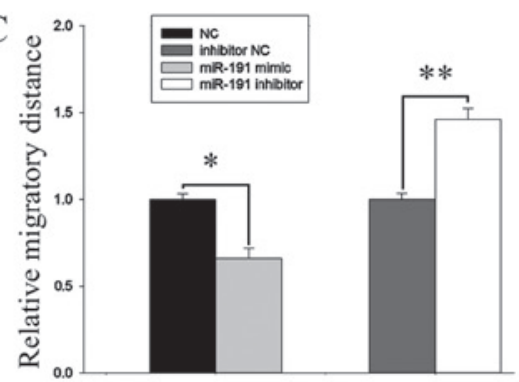

Figure 3. (A) Wound scratch assay demonstrating the migratory abilities of 786-O and ACHN cells. Analysis of migratory distances in (B) 786-O and (C) ACHN cells. ${ }^{*} \mathrm{P}<0.05$ and ${ }^{* *} \mathrm{P}<0.01$. miR, microRNA; NC, negative control; $\mathrm{T}$, time.

The results of the transwell assay (Fig. 4A) indicated that the migration rates in the miR-191-5p mimic group were significantly inhibited by $32.35 \%$ compared with the normal control $(\mathrm{P}<0.05$; Fig. 4B) and the invasion rates were 


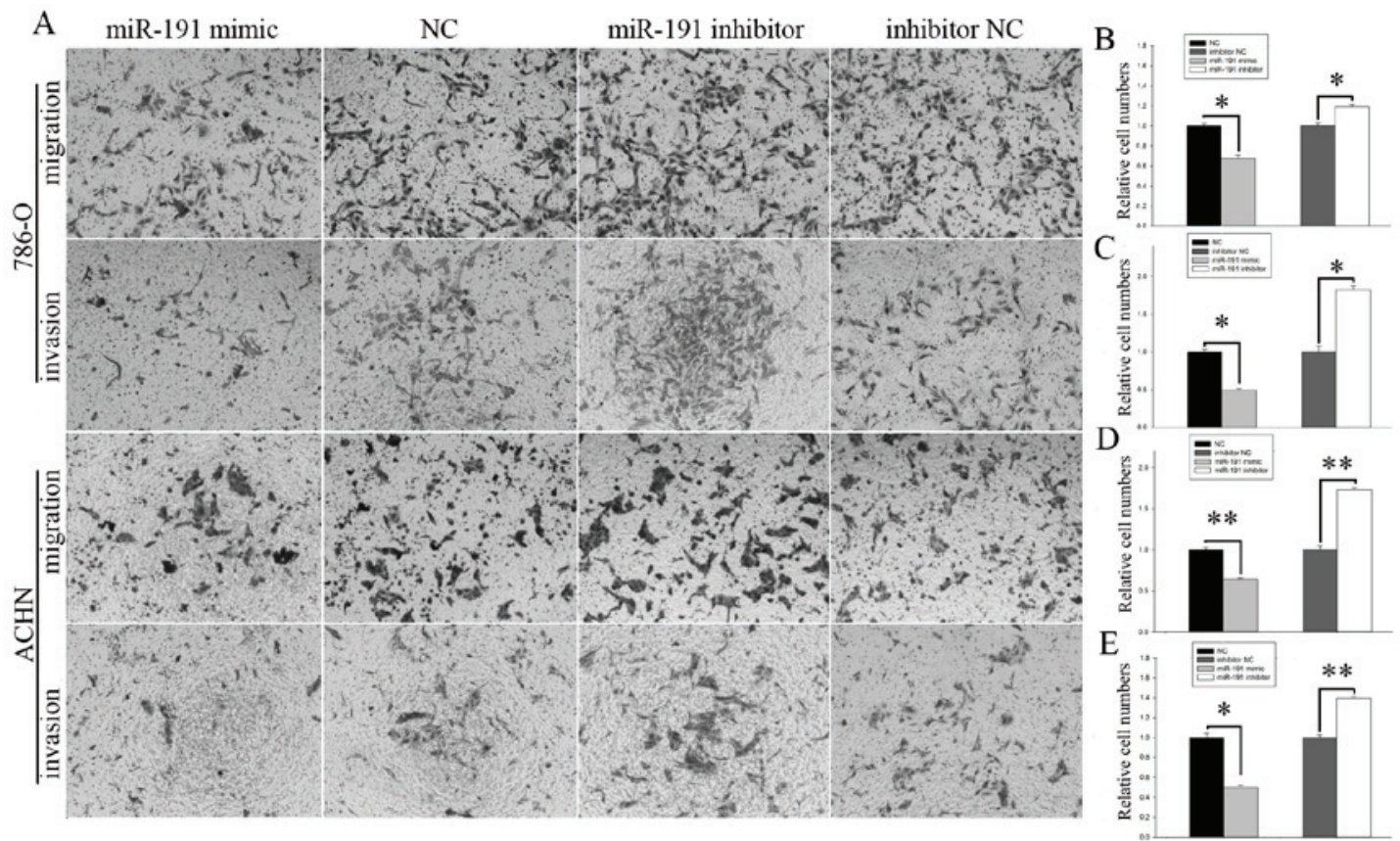

Figure 4. (A) Images of transwell assay of 786-O and ACHN cells. The (B) migration and (C) invasion of 786-O cells, and the (D) migration and (E) invasion of ACHN cells are demonstrated. ${ }^{*} \mathrm{P}<0.05$ and ${ }^{* *} \mathrm{P}<0.01$. miR, microRNA; NC, negative control.
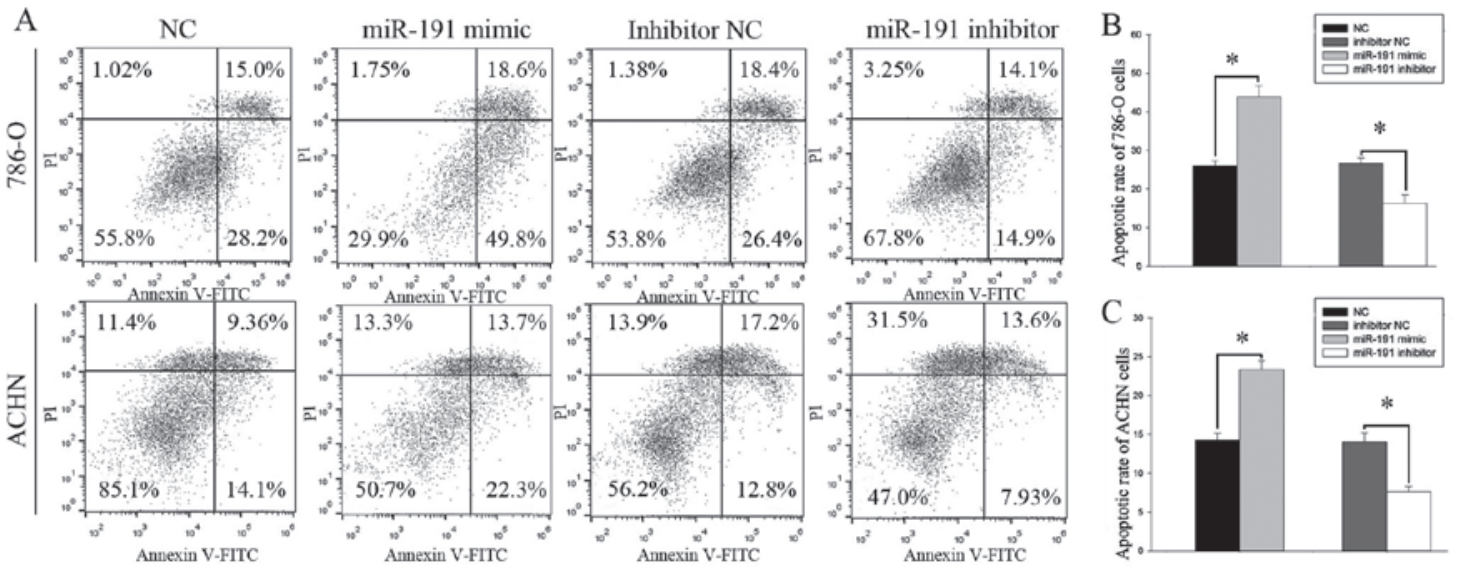

Figure 5. (A) Apoptosis investigated using flow cytometry assay. Analysis of early apoptotic rate in (B) 786-O and (C) ACHN cells. "P<0.05. miR, microRNA; PI, propidium iodide; FITC, fluorescein isothiocyanate; NC, negative control.

significantly reduced by $50.93 \%$ in $786-\mathrm{O}$ cells compared with the normal controls $(\mathrm{P}<0.05$; Fig. $4 \mathrm{C})$. The migration rates in the miR-191-5p mimic group were significantly inhibited by $35.36 \%$ compared with the normal control $(\mathrm{P}<0.01 ;$ Fig. 4D) and the invasion rates were significantly inhibited by $49.77 \%$ in the ACHN cells compared with the normal control group $(\mathrm{P}<0.05$; Fig. 4E). The migratory ability of the miR-191-5p inhibitor group was significantly increased by $19.02 \%$ compared with the normal control inhibitor group $(\mathrm{P}<0.05$; Fig. $4 \mathrm{~B})$ and the invasive ability of the miR-191-5p inhibitor group was significantly increased by $81.83 \%$ in $786-\mathrm{O}$ cells compared with the normal control inhibitor group ( $\mathrm{P}<0.05$; Fig. $4 \mathrm{C})$. Additionally, the migratory ability of the miR-191-5p inhibitor group was significantly increased by $73.16 \%$ compared with the normal control inhibitor group $(\mathrm{P}<0.01$; Fig. 4D) and the invasive ability of the miR-191-5p inhibitor group was significantly promoted by $39.74 \%$ in ACHN cells compared with the normal control inhibitor group $(\mathrm{P}<0.01$; Fig. 4E).

Upregulation of miR-191-5p induces cell apoptosis, whereas downregulation reduces cell apoptosis. The results of flow cytometry (Fig. 5A) revealed that the early apoptotic rate was significantly increased in the miR-191-5p mimic-transfected $786-\mathrm{O}$ cells in comparison with the NC-transfected cells (43.86 \pm 2.97 and $26.03 \pm 1.36 \%$; P $<0.05$; Fig. 5B). Similarly, the apoptotic rate was also markedly enhanced in the miR-191-5p mimic-transfected ACHN cells compared with the NC-transfected cells ( $23.33 \pm 1.13$ vs. $14.26 \pm 0.89 \%$; $\mathrm{P}<0.05$, Fig. 5C). Thus, miR-191-5p upregulation resulted in enhanced apoptosis in the two cell lines examined. In addition, the early apoptosis rate of 786-O cells transfected with $\mathrm{NC}$ inhibitor or miR-191-5p inhibitor was $26.66 \pm 1.41$ vs. $16.33 \pm 2.14 \%(\mathrm{P}<0.05$; 
Fig. 5B), while the ACHN cells transfected with $\mathrm{NC}$ inhibitor or miR-191-5p inhibitor was $14.03 \pm 1.20$ vs. $7.66 \pm 0.68 \%$ $(\mathrm{P}<0.05$; Fig. $5 \mathrm{C})$, indicating that downregulation of this miR reduced the cell apoptosis.

\section{Discussion}

The implication of miRNAs in tumorigenesis was first recognized when miRNA genes were observed to be specifically deleted in patients with leukemia (21). Subsequently, numerous studies demonstrated that miRNAs serve important roles in various carcinomas (22-26). In addition, Polioudakis et al (27) reported that miRNAs are located at $50 \%$ of all fragile regions or sites presenting copy number alterations in cancer.

The function of miR-191-5p differs among different tumors. According to the study of Tian et al (28), miR-191-5p inhibits tumor necrosis factor- $\alpha$-induced apoptosis in endometrial carcinoma cells by targeting death-associated protein kinase 1 (DAPK1). Additionally, Zhang et al (17) demonstrated that miR-191-5p promotes the tumorigenesis of colorectal cancer by targeting CCAAT-enhancer-binding protein $\beta$. Di Leva et al (29) also reported that expression of the miR-191/425 cluster reduced the proliferation and impaired tumorigenesis in breast cancer cells. However, Nagpal et al (30) reported that miR-191-5p functions as an estrogen inducible promoter in breast cancer by targeting SATB homeobox 1. Another study by Nagpal et al (31) confirmed that miR-191-5p promotes migration in breast cancer through complex regulation of transforming growth factor- $\beta$-signaling in a hypoxic microenvironment. miR-191-5p was further demonstrated to promote osteosarcoma cell proliferation by targeting checkpoint kinase 2, according to the study by Huang et al (32). It was also observed that miR-191-5p functions as a tumor promoter by modulating the tet methylcytosine dioxygenase 1-p53 pathway in intrahepatic cholangiocarcinoma (15). Recently, miR-191-5p has been revealed to promote pancreatic cancer progression by targeting ubiquitin specific peptidase 10 (33). Shi et al (34) reported that miR-191-5p exhibits a promotive effect by targeting $\mathrm{N}$-deacetylase and $\mathrm{N}$-sulfotransferase 1 in MGC803 human gastric cancer cells. In a lung cancer research, Xu et al (35) demonstrated that miR-191-5p positively modulated the epithelial-mesenchymal transition and cancer stem cell-like properties and functioned as an onco-miR in transfected cells. In addition, miR-191-5p overexpression has been observed in oral squamous cell carcinoma, although it remains unclear how it contributes to the development of this tumor. Furthermore, miR-191-5p is associated with poor prognosis in pancreatic cancer (36), chromophobe RCC (37), acute myeloid leukemia (38), glioblastoma (39) and malignant melanoma (40). In contrast to these previous studies, the present study observed that miR-191-5p was downregulated in RCC tissues and cells. In addition, miR-191-5p was observed to promote the proliferation, migration and invasion, as well as to inhibit the apoptosis, of 786-O and ACHN cells.

miR-191-5p is also known to serve an important role in non-neoplastic diseases. Previous studies have demonstrated that miR-191-5p may modulate the malignant transformation of endometriosis by targeting DAPK1 and TIMP metallopeptidase inhibitor $3(28,41)$.
According to a large number of studies, miR-191-5p has great potential for clinical use as a novel biomarker and as a therapeutic agent in cancer. Elyakim et al (42) reported that miR-191-5p inhibition has great potential in the treatment of hepatocellular carcinoma patients. In addition, miR-191-5p is a potential target in treating radiation-resistant lung cancer according to the study by Liu and Huang (43). Several studies also reported that miR-191-5p may be of value as a prognostic and predictive biomarker in certain tumors, including breast cancer (44), osteosarcoma (45), and head and neck squamous cell carcinoma (46). Furthermore, miR-191-5p was suggested to be a potentially non-neoplastic biomarker to diagnose traumatic brain injury and predict the patient prognosis (47).

In conclusion, in the present study, it was demonstrated that miR-191-5p was downregulated in 786-O and ACHN cells compared with the adjacent normal RCC cells. Downregulation of miR-191-5p promoted the proliferation, migration and invasion, as well as suppressed the apoptosis, of 786-O and ACHN cells. Further studies are required to uncover the underlying signaling pathway of miR-191-5p and to examine the potential role of miR-191-5p as a biomarker for early detection and prognosis prediction, and as a therapeutic target in RCC.

\section{Acknowledgements}

This study was supported by grants from the National Natural Science Foundation of China (no. 81101922), Science and Technology Development Fund Project of Shenzhen (nos. JCYJ20150403091443329 and JCYJ20170307111334308), the fund of 'San-ming' Project of Medicine in Shenzhen (grant no. SZSM201612066) and the fund of Guangdong Key Medical Subject.

\section{References}

1. Hsieh JJ, Purdue MP, Signoretti S, Swanton C, Albiges L, Schmidinger M, Heng DY, Larkin J and Ficarra V: Renal cell carcinoma. Nat Rev Dis Primers 3: 17009, 2017.

2. Fritz HK, Lindgren D, Ljungberg B, Axelson H and Dahlbäck B: The miR(21/10b) ratio as a prognostic marker in clear cell renal cell carcinoma. Eur J Cancer 50: 1758-1765, 2014.

3. Edge SB and Compton CC: The American Joint Committee on Cancer: The 7th edition of the AJCC cancer staging manual and the future of TNM. Ann Surg Oncol 17: 1471-1474, 2010.

4. Tusong H, Maolakuerban N, Guan J, Rexiati M, Wang WG, Azhati B, Nuerrula Y and Wang YJ: Functional analysis of serum microRNAs miR-21 and miR-106a in renal cell carcinoma. Cancer Biomark 18: 79-85, 2017.

5. Khella HWZ, Daniel N, Youssef L, Scorilas A, Nofech-Mozes R, Mirham L, Krylov SN, Liandeau E, Krizova A, Finelli A, et al: miR-10b is a prognostic marker in clear cell renal cell carcinoma. J Clin Pathol 70: 854-859, 2017.

6. Chen X, Wang X, Ruan A, Han W, Zhao Y, Lu X, Xiao P, Shi H, Wang R, Chen L, et al: miR-141 is a key regulator of renal cell carcinoma proliferation and metastasis by controlling EphA2 expression. Clin Cancer Res 20: 2617-2630, 2014.

7. Aguiari G: MicroRNAs in clear cell renal cell carcinoma: Biological functions and applications. J Kidney Cancer VHL 2: 140-152, 2015.

8. Yoshino H, Seki N, Itesako T, Chiyomaru T, Nakagawa M and Enokida H: Aberrant expression of microRNAs in bladder cancer. Nat Rev Urol 10: 396-404, 2013.

9. Jin L, Li Y, He T, Hu J, Liu J, Chen M, Zhang Z, Gui Y, Mao X, Yang S and Lai Y: miR-15a-5p acts as an oncogene in renal cell carcinoma. Mol Med Rep 15: 1379-1386, 2017.

10. Li Y, Li Y, Chen D, Jin L, Su Z, Liu J, Duan H, Li X, Qi Z, Shi M, et al: miR-30a-5p in the tumorigenesis of renal cell carcinoma: A tumor suppressive microRNA. Mol Med Rep 13: 4085-4094, 2016. 
11. Xu T, Qin L, Zhu Z, Wang X, Liu Y, Fan Y, Zhong S, Wang X, Zhang X, Xia L, et al: MicroRNA-31 functions as a tumor suppressor and increases sensitivity to mitomycin-C in urothelial bladder cancer by targeting integrin $\alpha 5$. Oncotarget 7 : 27445-27457, 2016.

12. Garzon R, Calin GA and Croce CM: MicroRNAs in Cancer. Annu Rev Med 60: 167-179, 2009.

13. Shenouda SK and Alahari SK: MicroRNA function in cancer: Oncogene or a tumor suppressor? Cancer Metastasis Rev 28: 369-378, 2009.

14. Guil S and Esteller M: DNA methylomes, histone codes and miRNAs: Tying it all together. Int J Biochem Cell Biol 41: 87-95, 2009.

15. Li H, Zhou ZQ, Yang ZR, Tong DN, Guan J, Shi BJ, Nie J, Ding XT, Li B, Zhou GW and Zhang ZY: MicroRNA-191 acts as a tumor promoter by modulating the TET1-p53 pathway in intrahepatic cholangiocarcinoma. Hepatology 66: 136-151, 2017.

16. Mar-Aguilar F, Luna-Aguirre CM, Moreno-Rocha JC, Araiza-Chávez J, Trevino V, Rodríguez-Padilla $\mathrm{C}$ and Reséndez-Pérez D: Differential expression of miR-21, miR-125b and miR-191 in breast cancer tissue. Asia Pac J Clin Oncol 9: 53-59, 2013.

17. Zhang XF, Li KK, Gao L, Li SZ, Chen K, Zhang JB, Wang D, Tu RF, Zhang JX, Tao KX, et al: miR-191 promotes tumorigenesis of human colorectal cancer through targeting $\mathrm{C} / \mathrm{EBPbeta}$. Oncotarget 6: 4144-4158, 2015.

18. Motzer RJ, Carducci MA, Fishman M, Hancock SL, Hauke RJ, Hudes GR, Kantoff P, Kuzel TM, Lange PH, Levine EG et al: Kidney Cancer. Clinical Practice Guidelines. J Natl Compr Canc Netw 3: 84-93, 2005.

19. Fuhrman SA, Lasky LC and Limas C: Prognostic significance of morphologic parameters in renal cell carcinoma. Am J Surg Pathol 6: 655-663, 1982.

20. Livak KJ and Schmittgen TD: Analysis of relative gene expression data using real-time quantitative PCR and the 2(-Delta Delta C(T)) method. Methods 25: 402-408, 2001.

21. Dyrskjøt L, Ostenfeld MS, Bramsen JB, Silahtaroglu AN Lamy P, Ramanathan R, Fristrup N, Jensen JL, Andersen CL, Zieger $\mathrm{K}$, et al: Genomic profiling of microRNAs in bladder cancer: miR-129 is associated with poor outcome and promotes cell death in vitro. Cancer Res 69: 4851-4860, 2009.

22. Kabir TD, Ganda C, Brown RM, Beveridge DJ, Richardson KL, Chaturvedi V, Candy P, Epis M, Wintle L, Kalinowski F, et al: A miR-7/GAS6/TYRO3 axis regulates the growth and invasiveness of sorafenib-resistant cells in human hepatocellular carcinoma. Hepatology, 2017.

23. Lynam-Lennon N, Heavey S, Sommerville G, Bibby BA Ffrench B, Quinn J, Gasch C, O'Leary JJ, Gallagher MF, Reynolds JV and Maher SG: MicroRNA-17 is downregulated in esophageal adenocarcinoma cancer stem-like cells and promotes a radioresistant phenotype. Oncotarget 8: 11400-11413, 2017.

24. Herr I, Sähr H, Zhao Z, Yin L, Omlor G, Lehner B and Fellenberg J: MiR-127 and miR-376a act as tumor suppressors by in vivo targeting of COA1 and PDIA6 in giant cell tumor of bone. Cancer Lett 409: 49-55, 2017

25. Yan J, Zhang Y, She Q, Li X, Peng L, Wang X, Liu S, Shen X, Zhang W, Dong Y, et al: Long Noncoding RNA H19/miR-675 axis promotes gastric cancer via FADD/Caspase 8/Caspase 3 signaling pathway. Cell Physiol Biochem 42: 2364-2376, 2017.

26. Yang Y, Ding L, Hu Q, Xia J, Sun J, Wang X, Xiong H, Gurbani D, Li L, Liu Y and Liu A: MicroRNA-218 functions as a tumor suppressor in lung cancer by targeting IL-6/STAT3 and negatively correlates with poor prognosis. Mol Cancer 16: 141, 2017.

27. Polioudakis D, Abell NS and Iyer VR: MiR-191 regulates primary human fibroblast proliferation and directly targets multiple oncogenes. PLoS One 10: e0126535, 2015.

28. Tian X, Xu L and Wang P: MiR-191 inhibits TNF- $\alpha$ induced apoptosis of ovarian endometriosis and endometrioid carcinoma cells by targeting DAPK1. Int J Clin Exp Pathol 8: 4933-4942, 2015.

29. Di Leva G, Piovan C, Gasparini P, Ngankeu A, Taccioli C, Briskin D, Cheung DG, Bolon B, Anderlucci L, Alder $\mathrm{H}$, et al: Estrogen mediated-activation of miR-191/425 cluster modulates tumorigenicity of breast cancer cells depending on estrogen receptor status. PLoS Genet 9: e1003311, 2013.
30. Nagpal N, Ahmad HM, Molparia B and Kulshreshtha R: MicroRNA-191, an estrogen-responsive microRNA, functions as an oncogenic regulator in human breast cancer. Carcinogenesis 34: 1889-1899, 2013.

31. Nagpal N, Ahmad HM, Chameettachal S, Sundar D, Ghosh S and Kulshreshtha R: HIF-inducible miR-191 promotes migration in breast cancer through complex regulation of TGF $\beta$-signaling in hypoxic microenvironment. Sci Rep 5: 9650, 2015.

32. Huang YZ, Zhang J, Shao HY, Chen JP and Zhao HY: MicroRNA-191 promotes osteosarcoma cells proliferation by targeting checkpoint kinase 2. Tumour Biol 36: 6095-6101, 2015.

33. Liu H, Xu XF, Zhao Y, Tang MC, Zhou YQ, Lu J and Gao FH: MicroRNA-191 promotes pancreatic cancer progression by targeting USP10. Tumour Biol 35: 12157-12163, 2014.

34. Shi X, Su S, Long J, Mei B and Chen Y: MicroRNA-191 targets $\mathrm{N}$-deacetylase/N-sulfotransferase 1 and promotes cell growth in human gastric carcinoma cell line MGC803. Acta Biochim Biophys Sin (Shanghai) 43: 849-856, 2011.

35. Xu W, Ji J, Xu Y, Liu Y, Shi L, Liu Y, Lu X, Zhao Y, Luo F, Wang B, et al: MicroRNA-191, by promoting the EMT and increasing CSC-like properties, is involved in neoplastic and metastatic properties of transformed human bronchial epithelial cells. Mol Carcinog 54 (Suppl 1): E148-E161, 2015.

36. Song Z, Ren H, Gao S, Zhao X, Zhang H and Hao J: The clinical significance and regulation mechanism of hypoxia-inducible factor-1 and miR-191 expression in pancreatic cancer. Tumour Biol 35: 11319-11328, 2014

37. Ge YZ, Xin H, Lu TZ, Xu Z, Yu P, Zhao YC, Li MH, Zhao Y, Zhong B, Xu X, et al: MicroRNA expression profiles predict clinical phenotypes and prognosis in chromophobe renal cell carcinoma. Sci Rep 5: 10328, 2015.

38. Ruvolo PP, Ruvolo VR, Jacamo R, Burks JK, Zeng Z, Duvvuri SR, Zhou L, Qiu Y, Coombes KR, Zhang N, et al: The protein phosphatase $2 \mathrm{~A}$ regulatory subunit B55 $\alpha$ is a modulator of signaling and microRNA expression in acute myeloid leukemia cells. Biochim Biophys Acta 1843: 1969-1977, 2014.

39. Tivnan A, Heilinger T, Ramsey JM, O'Connor G, Pokorny JL, Sarkaria JN, Stringer BW, Day BW, Boyd AW, Kim EL, et al: Anti-GD2-ch14.18/CHO coated nanoparticles mediate glioblastoma (GBM)-specific delivery of the aromatase inhibitor, Letrozole, reducing proliferation, migration and chemoresistance in patient-derived GBM tumor cells. Oncotarget 8: 16605-16620, 2017.

40. Caramuta S, Egyházi S, Rodolfo M, Witten D, Hansson J, Larsson C and Lui WO: MicroRNA expression profiles associated with mutational status and survival in malignant melanoma. J Invest Dermatol 130: 2062-2070, 2010.

41. Dong M, Yang P and Hua F: MiR-191 modulates malignant transformation of endometriosis through regulating TIMP3. Med Sci Monit 21: 915-920, 2015.

42. Elyakim E, Sitbon E, Faerman A, Tabak S, Montia E, Belanis L, Dov A, Marcusson EG, Bennett CF, Chajut A, et al: hsa-miR-191 is a candidate oncogene target for hepatocellular carcinoma therapy. Cancer Res 70: 8077-8087, 2010

43. Liu Z and Huang S: Inhibition of miR-191 contributes to radiation-resistance of two lung cancer cell lines by altering autophagy activity. Cancer Cell Int 15: 16, 2015.

44. Tajbakhsh A, Mokhtari-Zaer A, Rezaee M, Afzaljavan F, Rivandi M, Hassanian SM, Ferns GA, Pasdar A and Avan A: Therapeutic potentials of BDNF/ TrkB in breast cancer; current status and perspectives. J Cell Biochem 118: 2502-2515, 2017

45. Wang T, Ji F, Dai Z, Xie Y and Yuan D: Increased expression of microRNA-191 as a potential serum biomarker for diagnosis and prognosis in human osteosarcoma. Cancer Biomark 15: 543-550, 2015.

46. Salazar C, Nagadia R, Pandit P, Cooper-White J, Banerjee N, Dimitrova N, Coman WB and Punyadeera C: A novel saliva-based microRNA biomarker panel to detect head and neck cancers. Cell Oncol (Dordr) 37: 331-338, 2014.

47. Yang T, Song J, Bu X, Wang C, Wu J, Cai J, Wan S, Fan C, Zhang C and Wang J: Elevated serum miR-93, miR-191, and miR-499 are noninvasive biomarkers for the presence and progression of traumatic brain injury. J Neurochem 137: 122-129, 2016. 